\title{
Gamma oscillations as integrators of local competition for activity and global competition for coherence Thomas Burwick ${ }^{1,2}$
}

\begin{abstract}
Address: ${ }^{1}$ Frankfurt Institute for Advanced Studies (FIAS), Johann Wolfgang Goethe Universität, Ruth-Moufang-Str.1, 60438 Frankfurt am Main, Germany and ${ }^{2}$ Thinking Networks AG, Markt 45-47, 52062 Aachen, Germany
\end{abstract}

Email: Thomas Burwick - burwick@fias.uni-frankfurt.de

from Eighteenth Annual Computational Neuroscience Meeting: CNS*2009

Berlin, Germany. 18-23 July 2009

Published: 13 July 2009

BMC Neuroscience 2009, I0(Suppl I):P24 I doi:I0.II86/I47|-2202-I0-SI-P24 I

This abstract is available from: http://www.biomedcentral.com/I47I-2202/I0/SI/P24 I

(c) 2009 Burwick; licensee BioMed Central Ltd.

\section{Introduction}

Rhythmic synchronization of neural activity in the gamma-frequency range $(30-100 \mathrm{~Hz})$ was observed in many brain regions; see the review in [1]. The functional relevance of these oscillations remains to be clarified, a task that requires modeling of the relevant aspects of information processing. The temporal correlation hypothesis, reviewed in [2], proposes that the temporal correlation of neural units provides a means to group the neural units into so-called neural assemblies that are supposed to represent mental objects. Here, we approach the modeling of the temporal grouping of neural units from the perspective of oscillatory neural network systems based on phase model oscillators. Patterns are assumed to be stored in the network based on Hebbian memory and assemblies are identified with phase-locked subset of these patterns. Going beyond foregoing discussions, we demonstrate the combination of two recently discussed mechanisms, referred to as "acceleration" [3] and "pooling" [4]. The combination realizes in a complementary manner a competition for activity on a local scale, while providing a competition for coherence among different assemblies on a non-local scale.

\section{Modeling synchronization with acceleration and pooling}

The mentioned "pooling" mechanism refers to a network structure with macro- and mini-columnar architecture and local inhibition and synchronization, resulting in a competition for activity among the mini-columns in each macro-column [4]. The mentioned "acceleration" mecha- nism refers to an increase of phase velocity of a neural unit in case of stronger and/or more coherent input from the connected units. The oscillatory network model that we use is obtained from a complex-valued generalization of the classical Cohen-Grossberg-Hopfield model [3].

\section{Results}

Here, the two mechanisms are combined using a complex-valued gradient approach. We demonstrate the effect of this combination for a network with several stored patterns and input that activates a subset of patterns. On one hand, the pooling, based on local synchronization, establishes the local competition for activity of the neural units that are interpreted as mini-columns. On the other hand, the combination of global synchronization with acceleration implies the competition for coherence. The latter segregates the winning assembly among the active ones, by making it coherent, while the loosing assemblies return to states of de-coherence. Thereby, the two mechanisms may combine to select for the winning assembly as a result of a particular input.

\section{Conclusion}

In the review of the gamma cycle given in [1], it was emphasized that the gamma cycle may establish a winnertake-all behavior on a local scale and realize binding-bysynchrony on a global scale. It was claimed that "although the two hypothesis are distinct, they are fully compatible to each other" [1]. The present work is intended to be a step towards understanding the combination and com- 
patibility of the two functionalities from a modeling perspective.

\section{Acknowledgements}

It is a pleasure to thank $C$. von der Malsburg for valuable discussions. FIAS is supported by the Hertie-Foundation.

\section{References}

I. Fries P, Nikolic D, Singer W: The gamma cycle. Trends in Neurosciences 2007, 30:309-316.

2. Malsburg $C$ von der: The what and why of binding: the modeler's perspective. Neuron 1999, 24:95-104.

3. Burwick T: Temporal coding: assembly formation through constructive interference. Neural Computation 2008, 20:1796-1820.

4. Burwick T: On the relevance of local synchronization for establishing a winner-take-all functionality of the gamma cycle. Neurocomputing 2008 in press.

Publish with Bio Med Central and every scientist can read your work free of charge

"BioMed Central will be the most significant development for disseminating the results of biomedical research in our lifetime. "

Sir Paul Nurse, Cancer Research UK

Your research papers will be:

- available free of charge to the entire biomedical community

- peer reviewed and published immediately upon acceptance

- cited in PubMed and archived on PubMed Central

- yours - you keep the copyright

Submit your manuscript here:

http://www.biomedcentral.com/info/publishing_adv.asp 